Chemotherapy 1992;38(suppl 2):I-III

\title{
Contents, Vol. 38, Supplement 2, 1992
}

Dagan, R. Prefacel

Edwards, D.J.; Stoeckel, K. The Pharmacokinetics of New Oral Cephalosporins in Children 2

Cullmann, W. The Threat of Resistance to the New Oral Cephalosporins 10

Dagan, R. Clinical Studies in Pediatric Respiratory-Tract Infections: What is Desirable, Feasible, or Simply Misleading 18

Pukander, J.S.; Paloheimo, S.H.; Sipila, M.M. Cefetamet Pivoxil in Pediatric Otitis media 25

Paupe, J.; Sarbeji, M.; Scheinmann, P.; Delacourt, C; Sorin, M. Clinical Trial Pediatric

Lower-Respiratory-Tract Infection: Results and Comments with Cefetamet Pivoxil 29

Ramet, J.; Pierard, D.; Vandenberghe, P.; De Boeck, K. Comparative Study of Cefetamet Pivoxil and Penicillin V in the Treatment of Group A Beta-Hemolytic Streptococcal Pharyngitis 33

Syrogiannopoulos, G.A. Concluding Remarks 38 Author Index 40

Subject Index 40

in 